\title{
CARTA DO MODELADO E DAS FORMAÇÕES SUPERFICIAIS DO MÉDIO VALE DO RIO \\ PARATEÍ, SP - 1:25.000
}

\author{
Jean-Pierre COUTARD \\ Jöel PELLERIN \\ Marília BARROS DE AGUIAR \\ Lylian COLTRINARI
}

\begin{abstract}
RESUMO
Republicação da "Carta do Modelado e das Formações Superficiais do Médio Vale do Rio Parateí, SP - 1:25.000" e memorial explicativo, originalmente publicado em "Sedimentologia e Pedologia", número 9, pelo Instituto de Geografia, Universidade de São Paulo, São Paulo, em 1978. Pesquisa desenvolvida no âmbito do convênio entre o Laboratório de Pedologia e Sedimentologia do Instituto de Geografia / Departamento de Geografia da Faculdade de Filosofia, Letras e Ciências Humanas da Universidade de São Paulo e o Centro de Geomorfologia do CNRS - Caen, sob a coordenação de J.P. Queiroz Neto e A. Journaux.
\end{abstract}

Palavras-chave: Cartografia geomorfológica; Formações superficiais; Geomorfologia do Quaternário; Domínios paleoambientais.

\section{RÉSUMÉE}

CARTE DU MODELE ET DES FORMATIONS SUPERFICIELLES DE LA VALLÉE MOYENNE DO PARATEÍ, SP - 1:25.000. Réédition de la "Carte du Modele et des Formations Superficielles de la Vallée Moyenne do Parateí, SP - 1:25.000" et du commentaire, initialement publié dans "Sedimentologia e Pedologia", numéro 9, par l'Institut de Géographie de l'Université de São Paulo, São Paulo, en 1978. Recherches développés dans le cadre de l' accord entre le Laboratoire de Pédologie et Sédimentologie de l'Institut de Géographie / Département de Géographie de FFLCH de l'Université de São Paulo et du Centre de Géomorphologie du Centre National de la Recherche Scientifique - Caen, sous la coordination de J.P. Queiroz Neto et A. Journaux.

Mots clés: Cartographie géomorphologique; Formations superficielles; Géomorphologie Quaternaire; Paléoenvironnement.

\section{ABSTRACT}

MAP OF THE LANDFORMS AND SURFICIAL FORMATIONS OF THE MIDDLE VALLEY OF THE PARATEÍ RIVER, SP - 1: 25,000. Republication of the "Map of the Landforms and Surficial Formations of the Middle Valley of Parateí River, SP - 1: 25,000" and explanatory memorial, originally published in "Sedimentologia e Pedologia", number 9, by the Institute of Geography, University of São Paulo, São Paulo, in 1978. Research developed under the agreement between the Laboratory of Pedology and Sedimentology of the Institute of Geography / Department of Geography of FFLCH from the University of São Paulo and the Geomorphology Center of the CNRS in Caen, under the coordination of J.P. Queiroz Neto and A. Journaux.

Keywords: Geomorphological cartography; Surficial formations; Quaternary geomorphology; Paleoenvironmental domains. 


\section{INTRODUÇÃO}

A região cartografada situa-se no contato de duas unidades geológicas e geomorfológicas, separadas por importante escarpa de falha acompanhada pelo rio Parateí. No reverso, a noroeste, estende-se o compartimento gnáissico da Serra da Mantiqueira conhecido por bloco ou platô de Santa Isabel; a sudeste do rio Parateí, aparece a zona sedimentar da fossa tectônica do Paraíba e seus afluentes.

A região é bastante dissecada pela rede hidrográfica. No Pré-Cambriano, a drenagem principal ortogonal é condicionada pela estrutura, ao passo que, no sedimentar, é mais dendrítica, com os cursos principais paralelos entre si, de orientação NNW-SSE, concordante com o mergulho geral das camadas.

A escala da carta, 1:25.000, permitiu a representação das formas de detalhe do modelado e das formações superficiais, em detrimento das grandes formas de relevo.

\section{TOPOGRAFIA, LITOLOGIA, ESTRUTURA}

A escarpa de falha do Parateí, importante elemento da morfologia, de origem tectônica, apresenta orientação NE-SW, constituindo uma descontinuidade topográfica claramente visível na carta. Sua base foi exumada no Quaternário pelo entalhe fluvial. A escarpa está integrada a um contexto de feixe de falhas que estende-se desde São Paulo até Cruzeiro, e que originou a borda escarpada da serra da Mantiqueira nos limites das bacias de São Paulo e do médio Paraíba. A atividade tectônica responsável se fez sentir até o Terciário Superior.

A zona de falhas normais à que se vincula o escarpamento principal é indicada por diversos planos de deslocamentos, visíveis ao longo de cortes da rodovia D. Pedro I, e pelos alinhamentos de nascentes.

O Pré-Cambriano exibe também acidentes tectônicos transversais menos importantes, que causaram sua divisão em blocos, separados por vales profundos, bem como os deslocamentos no traçado da escarpa de falha do Parateí. No vale principal alternam-se estreitas passagens epigênicas em soleiras gnáissicas e trechos mais largos de várzeas, reflexo das variações de fácies da rocha.

A escarpa de falha principal, com altitude aproximada de $140 \mathrm{~m}$, apresenta aspectos variados.
Próximo aos deslocamentos transversais e às passagens epigênicas, exibe uma topografia mamelonada com escalonamento de níveis de colinas convexas de 630 a $700 \mathrm{~m}$; o topo das mais baixas pode ser relacionado ao glacis esculpido sobre o sedimentar, em particular próximo à passagem epigênica sul. $O$ trecho da escarpa próximo à Fazenda J. F. Borges é muito mais regular, apenas levemente entalhado por pequenas torrentes, cujos terços superiores são suspensos.

O substrato do platô é essencialmente constituído de gnaisse facoidal, com grandes cristais de feldspato e com biotita; entretanto, bruscas variações locais de fácies fazem aparecer granito-gnaisse, xisto-gnaisse, veios de quartzo, granitos, cataclasitos e milonitos.

Uma superfície de erosão eógena corta este conjunto entre 720 e $780 \mathrm{~m}$ de altitude aproximadamente. Numerosos cursos d'água, com talvegues entre 620 e $660 \mathrm{~m}$ de altitude, entalharam essa superfície, isolando morros policonvexos profundamente alterados (cortes da rodovia D. Pedro I).

A fossa do Parateí, contígua à do Paraíba, é preenchida por sedimentos detríticos miopliocênicos (Formação Superior Caçapava, da bacia de Taubaté), apresentando alternâncias verticais e laterais de argilas e areias feldspáticas, mais ou menos cascalhentas, por vezes recortadas por canais de materiais mais grosseiros.

A maior parte dos autores considera que a Formação Caçapava foi depositada sob clima semiárido, devido às características e variações faciológicas dos sedimentos, que indicam escoamento em canais anastomosados e zonas de decantação, à grande quantidade de feldspatos e à presença de argilas esmectíticas.

Na bacia de Taubaté, situada mais a jusante, a espessura dessa formação é superior a $200 \mathrm{~m}$. Aqui, constatou-se ser menos espessa, de 20 a mais de $60 \mathrm{~m}$, com eventuais afloramentos do embasamento gnáissico como, por exemplo, ao norte da Fazenda da Canga, no trecho mais oriental da zona cartografada, comprovando a irregularidade do relevo fossilizado pela sedimentação terciária.

O sedimentar é cortado por uma superfície levemente inclinada para NNW, cuja altitude decresce de 660 a $600 \mathrm{~m}$, recortada por numerosos vales encaixados 40 a $50 \mathrm{~m}$. Os níveis argilosos e areníticos principais da Formação Caçapava 
condicionam a formação de pequenas cornijas estruturais nas vertentes.

\section{FORMAS E FORMAÇÕES LIGADAS AO ESCOAMENTO CONCENTRADO}

No platô de Santa Isabel, as nascentes permanentes originam a formação de nichos e, igualmente, de numerosos e vastos anfiteatros, normalmente amplos, com forma regular e podendo atingir até as meias vertentes. Processos de solubilização e o carreamento de argilas e areias finas e médias provocam uma movimentação descendente progressiva da cobertura coluvial do interior dos anfiteatros, originando degraus ou "terrassetes". O desenvolvimento rápido dessas formas é compreensível ao considerar-se a espessura do manto de alteração, que permite importante estocagem d'água.

Alguns nichos, anfiteatros e cabeceiras de pequenos ravinamentos de altas vertentes não são mais funcionais e suas formas originais se degradaram, tendo sido representados com traços interrompidos. Este tipo de evolução é ocasionado pelo abaixamento progressivo dos lençóis freáticos, à medida que se encaixam os cursos principais e, também, pela formação de anfiteatros de escorregamento em massa, provocados por solapamentos de baixa vertente.

Fatos semelhantes também ocorrem na zona sedimentar, com vários exemplos ao norte da igreja $\mathrm{N}^{\mathrm{a}}$. Sr ${ }^{\mathrm{a}}$. dos Remédios.

Os vales do Pré-Cambriano têm forma geral em $V$; entretanto, muitos apresentam aspecto particular de bacias ou calhas escalonadas, para onde convergem e justapõem-se diversas ravinas, pequenos vales e anfiteatros de nascentes. Este escalonamento associa-se a estreitamentos do vale, onde os rios atravessam soleiras rochosas. Os afluentes do Parateí que entalham a escarpa de falha formam rápidos e cascatas, com belos exemplos no bairro rural de Figueira e na Fazenda J.F. Borges. Tanto na escarpa principal como nas passagens epigênicas, as vertentes exibem declividade e denudação acentuadas, ressaltando "chicots" rochosos, campos de matacões e de blocos.

No reverso do platô gnáissico, os pequenos vales com escoamento temporário, suspensos em relação ao nível de base local, apresentam forma em berço ou com fundo chato, colmatados por colúvios (exemplos ao longo da rodovia D. Pedro I ao norte da carta).
No sedimentar, os pequenos vales apresentam formas mais variadas. Três episódios morfogenéticos foram constatados durante $\mathrm{o}$ levantamento de campo, explicando esse fato: uma primeira fase de entalhe, importante, foi seguida por espessa colmatagem por coluviões, terminando por uma fase de erosão linear recente. Esta última não atingiu a mesma intensidade em toda a área, originando a variedade de formas registrada nos vales.

As formas em berço são frequentes nas cabeceiras dos subafluentes do Parateí ou dos pequenos vales de $3^{a}$ ordem, que não foram atingidas pela erosão linear atual (exemplos no bairro rural de Mandi, ao sul da carta). Além disso, nem todos os pequenos canais que entalham as vertentes possuem escoamento superficial e, comumente, conservam formas em berço (exemplo sobre a margem direita do riacho da Fazenda Antônio Bernardino, próximo à ferrovia). Diversos cortes ao longo da rodovia Presidente Dutra mostram tratar-se, em muitos casos, de vales em $V$ que assumiram forma em berço por colmatagem coluvial.

Na maior parte dos vales dos subafluentes do Parateí, a erosão foi bastante ativa e cresce à montante, uma incisão em $V$ que passa, a jusante, para fundo chato, devido ao aluvionamento arenoso ou areno-argiloso; os principais afluentes chegam a formar várzeas arenosas com largura de 100 a $150 \mathrm{~m}$.

Vales desnudados destacam-se, correspondendo a cursos muito curtos e nitidamente encaixados, com paredes laterais e cabeceiras de forte declividade, por vezes subvertical, e quase nenhuma cobertura coluvial. Os bancos de arenito e de argila formam ressaltos nas vertentes, e seus afloramentos ocasionam linhas de ressudação. $\mathrm{O}$ fundo desses vales é quase chato, recoberto por colúvios e levemente entalhado por escoamentos temporários fracos (bairros rurais de Parateí, Mandi e Ijal).

Finalmente, os vales dissimétricos achamse bem representados no sedimentar, possuindo ou não fundo chato. Sua dissimetria vincula-se às diferenças de declividade entre as vertentes, proximidade da rocha e processos de elaboração do modelado. São dissimétricos quase todos os vales dos afluentes dos cursos d'água situados imediatamente a leste da ferrovia, próximos à Capela Santana. As vertentes com exposição NNW têm declividade relativamente menor e estão regularizadas por coluvionamento. 
As vertentes com exposição SSE apresentam declividade mais acentuada; sua parte alta, tendo sofrido uma erosão mais intensa, exibe pequenas cornijas rochosas (estratos de arenito e de argila). A dissimetria dos vales parece estar relacionada ao mergulho geral das camadas sedimentares para NNW, observado diversas vezes no decorrer do levantamento de campo e assinalado por TITARELLI (1975). Enquanto as vertentes com menor declividade são conformes ao mergulho, as mais íngremes são contrárias.

No vale do Parateí alternam-se estreitas passagens epigênicas sobre gnaisse e setores de várzea no sedimentar, cuja largura chega a atingir $600 \mathrm{~m}$. Os lençóis aluviais e os terraços fluviais, indicadores das etapas da evolução do entalhamento do rio, de modo geral encontram-se mal conservados e na maior parte recobertos por colúvios. Mesmo assim, alguns desses elementos podem ser destacados. Próximo à passagem epigênica meridional, na Fazenda Sociedade Civil do Parateí, existem alguns patamares 25 a $30 \mathrm{~m}$ acima do nível da várzea, contendo restos de depósitos de blocos e seixos, muito alterados, relacionados ao glacis plio-quaternário esculpido sobre o sedimentar. Outro nível de terraços e lençóis aluviais situa-se, aproximadamente, 8 $\mathrm{m}$ acima da várzea (III); a camada de seixos, de 60 a $80 \mathrm{~cm}$ de espessura, acha-se sob areias cascalhentas cuja espessura também pode atingir $80 \mathrm{~cm}$, estando todo o conjunto recoberto por colúvios. Os seixos, entre 2 e $10 \mathrm{~cm}$ de diâmetro (alguns até $20 \mathrm{~cm}$ ), são formados por quartzo, quartzitos e, em menor quantidade, fragmentos de couraça, estão pouco alterados e levemente ferruginizados na superfície, com patina; esses depósitos aluviais, em alguns locais, acham-se fracamente cimentados por ferro e manganês. Os baixos lençóis aluviais (IV), situados 1,5 a $2 \mathrm{~m}$ acima do nível da várzea, exibem uma associação de areias e níveis de seixos com matriz arenosa, com espessura total da ordem de 1,2 a 1,4 m. Os seixos de quartzo e de quartzito encontram-se muito pouco alterados e levemente coloridos por ferro. Os dois conjuntos descritos anteriormente, datam, provavelmente, do Quaternário Médio.

Depósitos mais recentes preenchem a várzea do Parateí, com espessura total variando de 8 a $10 \mathrm{~m}$ nos cortes próximos às olarias do ângulo SW da carta. A base destes depósitos é formada por uma camada de seixos não alterados, com espessura média de $1 \mathrm{~m}$; acha-se recoberta por uma sucessão de estratos e lentes de areias e argilas. Nas camadas de areias são encontrados troncos de árvores, fragmentos de galhos e folhas, pertencentes a espécies de ASPIDOSDERMA, NECTANDRA, FICUS, TABEBUIA e CEDRELA (TITARELLI 1975), que ocorrem na floresta tropical úmida atual.

A presença de grande quantidade de troncos entre os sedimentos da várzea levanta o problema da origem. Poderia testemunhar processos fluviais espasmódicos relacionados a uma oscilação climática durante o Holoceno, sugerida por várias datações em torno de 2400 e 2700 BP do sul do Brasil. Segundo outra hipótese, poderiam os troncos ser consequência de precipitações de intensidade excepcional, como as de Caraguatatuba em 1967 e Tubarão em 1974. Neste caso, teria ocorrido solapamento da base das encostas e das margens dos rios, causando escorregamentos e o arrastamento das árvores das florestas-galeria e das que recobriam as vertentes.

A sedimentação que se processa atualmente junto aos rios é arenosa a mais argilosa nas zonas de transbordamento. Alguns cones aluviais areno-argilosos estão sendo construídos por alguns afluentes do Parateí.

\section{FORMAS E FORMAÇÕES DE VERTENTE}

Foram caracterizados dois conjuntos de formas e de formações superficiais: um deles, cartografado em verde azulado, refere-se aos movimentos de massa, enquanto o outro, representado em verde-mostarda, corresponde aos colúvios.

a) Movimentos de massa

$\mathrm{Na}$ região cartografada, a solifluxão não é processo generalizado, tanto no cristalino como no sedimentar. Várias razões parecem justificar esse fato: ausência de lençóis freáticos importantes com emergências contínuas nas vertentes, permitindo a saturação das formações superficiais; homogeneidade dessas formações, não favorecendo a ocorrência de bolsões saturados d'água; pouca plasticidade desses materiais, com quantidades importantes de areia e microagregados argilosos. Dessa maneira, os movimentos de massa do tipo solifluxão são pontuais.

No Pré-Cambriano, a rocha sã abaixo dos colúvios e alterações aparece a profundidades variáveis. Isso favorece localmente acúmulos de 
umidade no solo e provoca movimentos coletivos, originando anfiteatros de solifluxão, como os que se observam nas vertentes dos vales próximos à Fazenda J. F. Borges.

O processo dominante, na realidade, é o escorregamento em prancha, como foi assinalado próximo à Fazenda São João, ao norte. Aí, uma camada relativamente pouco espessa de colúvios (1 a 2,5 m) foi arrastada após supersaturação rápida do material, quando de períodos curtos (15 a 20 dias) de chuvas intensas e concentradas. Desse modo, novas formas de escorregamento apareceram no início de 1977, em particular na Faz. Três Santos, próximo à passagem epigênica sul.

$\mathrm{Na}$ zona sedimentar, as alternâncias de lentes arenosas e argilosas multiplicam os níveis d'água e os movimentos de massa são consequentemente muito mais dispersos. Os colúvios saturam-se realmente apenas nas baixas vertentes, onde concentram-se as soluções que movimentam-se hipodermicamente. Antigas calhas que modelaram as vertentes e que hoje acham-se recobertas por colúvios, sofrem a ação dessa concentração das soluções que favorece a formação de alguns movimentos de massa como na margem direita do rio Cambará.

Outra causa dos movimentos de massa na região sedimentar é o solapamento das baixas vertentes pelos cursos d'água; a retirada dos materiais da base desequilibra a vertente, propiciando a formação de escorregamentos e o abatimento do recobrimento em degraus sucessivos. Por estarem diretamente relacionadas à ação dos cursos d'água estas formas são muito abundantes à montante dos subafluentes do Parateí, trechos onde a erosão é muito ativa, como ao sul do Bairro rural de Ijal.

Constata-se que, no maciço antigo e na zona sedimentar, a maior parte dos grandes movimentos de massa ocorrem sobre vertentes com orientação $\mathrm{S}$ e $\mathrm{SW}$, provavelmente mais úmidas por serem frontais às direções dominantes de chuvas.

\section{b) Coluvionamentos}

Nas colinas do platô gnáissico a espessura das alterações, apesar de variável, é sempre elevada. Os cortes da rodovia D. Pedro I, em direção à Igaratá, mostram 15 a $30 \mathrm{~m}$ de rocha decomposta onde aparecem latossolos vermelho-amarelos com espessura de 1 a $5 \mathrm{~m}$. Nos vales rejuvenescidos com vertentes de forte declividade, ocorrem colúvios de coloração bruno avermelhada ou vermelho amarelada, com espessuras de $1 \mathrm{~m}$ nas partes altas e 2 a 2,5 $\mathrm{m}$ nas baixas. Localmente, nas baixas vertentes e cabeceiras de vales, várias fases de coluvionamento são reconhecidas, separadas por paleossolos com $\mathrm{Bt}$ ou horizontes humíferos enterrados. Entre os colúvios e a rocha alterada é comum ocorrer uma "stone-line" formada de fragmentos de quartzo de veio e, por vezes, de seixos provenientes de antigos depósitos de glacis ou aluviais. Nas baixas vertentes a espessura das "stone-lines" pode atingir 40 a $60 \mathrm{~cm}$.

Nos interflúvios do sedimentar podem ocorrer afloramentos de rocha alterada ou formações argilo-arenosas pouco espessas (menos de $1 \mathrm{~m}$ ), separadas do substrato por uma "stoneline" de grânulos e seixos de quartzo, quartzito e fragmentos de couraça; por vezes, essas formações coluviais são mais espessas (2 a 3,5 m), mostrando latossolos vermelho-amarelos. Nas vertentes é comum a ocorrência de dois colúvios superpostos, separados por "stone-lines" de 5 a $15 \mathrm{~cm}$, assinalados na carta por um triângulo. É preciso ressaltar o caso das vertentes irregulares, originadas por uma sucessão de episódios de erosão e coluvionamento. Quatro fases principais foram identificadas: uma incisão, seguida por deposição de colúvios avermelhados; uma segunda fase de erosão moderada, com formação de canais menos profundos e de uma "stone-line", é seguida por uma última fase de coluvionamento amarelado. Esse tipo de modelado de vertentes é muito comum nas proximidades das Fazendas Korao Kano e Antônio Bernardino.

Os vários estratos argilosos do sedimentar determinam a presença de lençóis suspensos temporários, que provocam fenômenos localizados de hidromorfia nos colúvios. Estes apresentam, em alguns pontos, placas de arenito ou de couraça ferruginosa desmantelada.

\section{FORMAS POLIGÊNICAS}

Correspondem à formas côncavas, ovais ou circulares, de dimensão hectométrica ou decamétrica, cujas formações parecem vinculadas a processos variados.

Os alvéolos nos gnaisses atingem até 500 $\mathrm{m}$ de dimensão, exibindo fundo chato. Achamse próximos aos restos mais elevados dos testemunhos da superfície antiga do platô de Santa Isabel, que separam as bacias do Jaguarí 
e do Parateí, a leste da capela das Brotas e ao norte da Fazenda J.F. Borges. Situam-se sobre cruzamento de fraturas e originam-se provavelmente por alteração diferencial da rocha. Atualmente são entalhadas e a exportação do material é feita parcialmente sob forma solúvel ou de partículas sólidas (areias e argilas), pelo escoamento superficial.

As depressões fechadas são formas menores, com 10 a 20 m de diâmetro. Ocorrem sobre os testemunhos da superfície cimeira de Santa Isabel ou em colos elevados do Pré-Cambriano. Apresentam com frequência algum alinhamento, relacionado às direções de fraturas do substrato. Muitas dessas depressões preenchem-se de água durante a estação chuvosa.

\section{FORMAÇÕES LIGADAS AO CLIMA TROPICAL SECO}

Admite-se que a superfície cimeira que aplainou os topos do Pré-Cambriano tenha sido elaborada sob clima semiárido, mas nenhum depósito correlativo desse episódio foi encontrado na região cartografada.

Por outro lado, o glacis sustentado pelo sedimentar, degradado pelos entalhes do Parateí e afluentes, apresenta ainda localmente restos de formações de seixos e de couraças. O glacis inclina-se fracamente em direção ao Parateí (altitudes decrescentes de 660 a $635 \mathrm{~m}$ ) e apoiase a SE, sobre as elevações da Serra do Itapeti, cuja altitude máxima é de 1169 m (fora da carta). Nas proximidades da passagem epigênica sul, nas vizinhanças da Fazenda Sociedade Civil do Parateí, ocorrem restos de material grosseiro de glacis, tanto sobre o Pré-Cambriano como sobre o sedimentar. É constituído por seixos de 1,5 a $6 \mathrm{~cm}$ de diâmetro e por blocos de até 30 ou $35 \mathrm{~cm}$, de quartzo e quartzito, rolados ou apenas desarestados e profundamente alterados, recobertos por película ferruginosa castanhoescuro espessa.

A superfície do glacis foi encouraçada, como testemunham os fragmentos residuais que possuem, frequentemente, $1 \mathrm{~m}$ de comprimento por $70 \mathrm{~cm}$ de espessura, e aparecem sobre um certo número de interflúvios, como nos topos das colinas situadas entre a ferrovia e o escarpamento gnáissico. A difratometria de raios $\mathrm{X}$ indica que essa couraça é constituída por hematita dominante, de goethita e caulinita.
Para melhor ressaltar sua extensão, os fragmentos de couraça, misturados aos depósitos de vertente, foram cartografados em vermelhoalaranjado.

\section{AÇÕES ANTRÓPICAS}

As voçorocas e ravinas parecem pouco numerosas na região do médio vale do Parateí, se compararmos com outras regiões do Estado de São Paulo, onde as coberturas arenosas são bastante extensas (ver cartas de São Pedro e de Marília).

Algumas dessas formas achamse estabilizadas por reflorestamento, por modificações no uso do solo ou modificação no regime hídrico. Grande parte das parcelas ainda submetidas a uma erosão antrópica intensa situase próximo às grandes áreas para construção de estradas (rodovias Presid. Dutra e D. Pedro I, ferrovia RFFSA) que deslocaram quantidades consideráveis de materiais, modificando as condições de drenagem, colocando o substrato a descoberto e criando aterros muito sensíveis à erosão. Além disso, as águas pluviais, concentradas nas sarjetas, são lançadas sobre as vertentes, onde escavam sulcos, ravinas e voçorocas profundas.

Sobre as vertentes ocorre, ainda atualmente, um escoamento difuso que arrasta as areias dos horizontes A dos solos, sendo comum encontrar-se pequenos horizontes humíferos recobertos de areias esbranquiçadas ou amareladas, acumuladas numa espessura de 50 a $80 \mathrm{~cm}$. Mais grave para a conservação dos solos, o escoamento pode atingir um primeiro estágio de concentração sob a forma de pequenos sulcos, cujos exemplos mais marcantes foram cartografados ao sul da Fazenda Sociedade Civil do Parateí. A cultura de café, no passado, as plantações de eucaliptos de hoje, favoreceram o processo de desenvolvimento de sulcos entre os troncos, após o corte das árvores.

Seria necessário acrescentar, nos fatos assinalados sobre a carta, a modificação total de numerosas vertentes, transformadas em longos terraços artificiais para a construção de diversas granjas e estufas. Esta modificação rápida da ocupação do solo parece não ter, ainda, causado fenômenos de erosão. 
Autores consultados:

A.N. Ab'Sáber, F.F.M. Almeida, A. Bjornberg, C. Carneiro, J. Cavalcante, L. Coltrinari, C.P. Couto, R.O. Freitas, Y. Hasui, S. Mezzalira, J. Rich, K. Suguio, A. Titarelli, J. Tricart.

\section{Créditos:}

Redação do memorial explicativo:

J.P. Coutard e J. Pellerin (Centre de Géomorphologie du CNRS); M. Barros de Aguiar (Laboratório de Pedologia e Sedimentologia - Inst. Geog. - USP); L. Coltrinari (Departamento de Geografia - FFLCH USP).

Levantamento de campo e preparação da carta:

L. Coltrinari, P. Nakashima, E. Neves Domingues, M.S.L. Silveira Reis (Departamento de Geografia FFLCH - USP); M. Barros de Aguiar, A. Baptista Pereira, M. Barcosa de Leon, C. Marotta Melfi, M.T. Nóbrega, A. Scatolini Watanabe, S.M. Stanowski (Laboratório de Pedologia e Sedimentologia - Inst. Geog. - USP); J.P. Coutard, e J. Pellerin (Centre de Géomorphologie du CNRS).

Análises Químicas:

J.M.A.S. Valadares (IAC - Seção de Pedologia).

Desenho das maquetes definitivas:

M. Barros de Aguiar e Terrafoto S.A.

Organismos que financiaram as pesquisas:

Universidade de São Paulo: Faculdade de Filosofia, Letras e Ciências Humanas, Instituto de Geografia; Secretaria de Cultura, Ciência e Tecnologia do Estado de São Paulo: Departamento de Ciências Exatas e Tecnologia (DCET) e Fundação de Amparo à Pesquisa do Estado de São Paulo (FAPESP); Service de Coopération Technique et Scientifique, Ministère des Affaires Etrangères, France e Centre de Géomorphologie du Conseil National de la Recherche Scientifique (CNRS), Caen, France. 